\title{
Ion-induced luminescence control in pyrene-tethered bipyridine ligand systems
}

\author{
S. Leroy, T. Soujanya, J.-E. Sohna Sohna, and F. Fages \\ Group of Supramolecular Chemistry and Catalysis, UMR 5802, Université Bordeaux 1, 33405 Talence Cedex, France
}

\begin{abstract}
A series of tunable fluorophores combining the pyrene nucleus and the 2,2'-bipyridine ligand unit are presented. They were designed to display luminescence tuning upon metal ion complexation. The effects are strongly affected by the nature of the covalent bridge linking the two subunits. The intensity, the color, but also the lifetime of the luminescence emission are features that can be finely modulated depending on the molecular structure, the nature of the solvent and the metal cation. This approach provides accesss to a new class of photosensitive receptors for applications in chemosensing, optoelectronic, or solar energy storage and conversion.
\end{abstract}

\section{INTRODUCTION}

Since the pioneering work of Auguste Laurent, who in the mid-19th century reported the first isolation of pyrene from coal tar [1], this polycyclic aromatic hydrocarbon has been the subject of tremendous investigation, and still remains a chromophore of choice in fundamental and applied research areas as diverse as organic chemistry, chemical physics, material science, biology, electroluminescence, fluorescent labelling, electrophotography, etc. Indeed pyrene and its derivatives combine a large series of convenient attributes, such as easiness of preparation and purification, high molar extinction coefficients above $300 \mathrm{~nm}$, high fluorescence quantum yields in most media, long-lived lowest excited singlet state in deoxygenated solvents, photochemical inertness under classical experimental conditions, and versatile redox properties. The pyrene chromophore hence attracted much interest in the field of supramolecular chemistry as fluorogenic unit to be incorporated into photoactive systems endowed with molecular recognition properties [2, 3]. The design and synthesis of such systems operating signal tranduction upon an external stimulus is of paramount importance for the development of functional molecular-scale devices for information processing, storage and transport [2]. Particularly, photosensitive molecular receptors, combining an aromatic fluorophore as reporter moiety and a binding unit functioning as a recognition site, were shown to act as tunable fluorogenic multi-component systems whose fluorescence output is highly sensitive to chemical inputs, such as proton or metal ion concentration jumps [3, 4]. Chemosensing or optical switching represent tremendously exciting applications [2-4].

In this contribution, we focus on the research effort we have been pursuing for the last five years on the investigation of supramolecular receptors specifically designed to display fluorescence tunability upon bind- ing of transition metal ions. This paper is devoted to that class of ligands in which the pyrene chromophore is covalently tethered to the $2,2^{\prime}$-bipyridine (bpy) subunit. Indeed they are well-suited for the complexation of divalent transition-metal ions [5]. Interestingly, they also enable the generation of polychromophoric pyrene-Ru(II) structures with outstanding photophysical properties owing to the peculiar spectroscopic features of pyrene.

\section{PYRENE-BIPYRIDINE LIGANDS CONNECTED BY A FLEXIBLE LINK}

We have synthesized and investigated a series of pyrene-tethered ligand systems containing one, two, and three bpy moieties, such as the compounds $\mathbf{1}$, 2 , and 3, respectively [6-8]. These molecules share in common the fact that the pyrene chromophore retains its photophysical indentity in the free ligands. Indeed the data for the monochromophoric bidentate ligand 1 [9] (Table 1) indicate the absence of any significant interaction between pyrene and bpy termini in both the ground and excited states, compound 1 displaying the typical behavior of alkyl-substituted pyrene derivatives, as compared to the reference compound 1-ethylpyrene. In contrast, the photophysical properties of compounds 1-3 are dramatically altered by the binding of metal cations to the nitrogen atoms of the bidentate bpy ligand unit. While the addition of one equivalent of inherently quenching transition metal ions, such as copper(II) for example, induces the expected fluorescence intensity decrease, the same effect was also observed when the closed-shell divalent zinc ion was used. Under the same conditions, the fluorescence of the reference chromophore 1-ethyl-pyrene was unchanged. The photophysical effect of zinc(II) was particularly investigated in the case of ligand 2 which was shown to form a 1:1 zinc(II)/ 2 complex in solution, thereby leading to an increase of the reduction potential of the 
<smiles>c1ccc(-c2ccc(COCc3ccc4ccc5cccc6ccc3c4c56)cn2)nc1</smiles><smiles>O=C(NCc1ccc(-c2ccccn2)nc1)c1cc(OCc2ccc3ccc4cccc5ccc2c3c45)cc(C(=O)NCc2ccc(-c3ccccn3)nc2)c1</smiles><smiles>O=C(CCOCC(COCCC(=O)NCc1ccc(-c2ccccn2)nc1)(COCCC(=O)NNCc1ccc(-c2ccccn2)nc1)NC(=O)Cc1ccc2ccc3cccc4ccc1c2c34)NCc1ccc(-c2ccccn2)nc1</smiles>

Scheme 1.

bpy fragments upon complexation of the hard Lewis acid zinc(II) [7]. Accordingly, an intramolecular photoinduced electron transfer (PET) process was proposed to account for the quantitative fluorescence quenching of the photoexcited pyrene nucleus by the zinc(II)containing moiety. Therefore, the pyrene-bpy interaction, silent in the free ligand, becomes effective in the metal complex, which leads to effective ON/OFF fluorescence switching. Actually this behavior is reminiscent of the work by A. P. de Silva which reported the use of a related anthracene-appended bpy ligand for the generation of optical switching devices [3].

These systems appear particularly interesting to construct multichromophoric assemblies allowing to study the photophysical interplay between pyrene and $\left[\mathrm{Ru}(\mathrm{bpy})_{3}\right]^{2+}$ subunits. Indeed, recent work has shown that among the number of $\left[\mathrm{Ru}(\mathrm{bpy})_{3}\right]^{2+}$. incorporating dyads bearing a pendant polycyclic aromatic moiety, those based on the pyrene chromophore were of particular interest due to the quasi isoenergetic position of the triplet excited state of the metal complex and the pyrene. This feature is unique as it allows triplet electronic energy transfer to take place efficiently between the two partners, the result of which being a dramatic extension of the triplet lifetime of the $\left[\mathrm{Ru}(\mathrm{bpy})_{3}\right]^{2+}$ chromophore [11]. This led us to synthesize the ruthenium(II) species based on the ligands 1-3. For the 1-Ru complex, Table 1 shows that selective excitation of either the pyrene or the $\left[\mathrm{Ru}(\mathrm{bpy})_{3}\right]^{2+}$ chromophore is feasible. Actually fluorescence emisssion from the aromatic pyrene chromophore was found to be quenched efficiently, and a long-lived ${ }^{3} \mathrm{MLCT}$ emis$\operatorname{sion}(\tau=10.5 \mu \mathrm{s})$ was observed, irrespective of the excitation wavelength. The lifetime value much exceeds that of the parent complex $\left[\mathrm{Ru}(\mathrm{bpy})_{3}\right]^{2+}$, a 10 -fold prolongation being noticed. This effect is probably due to the high conformational flexibility of the oxygen atomcontaining chain, which has been shown to allow a close end-to-end approach between termini during in excitedstate bichromophoric systems [12]. Of special interest was compound 3 as it enabled the generation of a $\mathrm{Ru}$ (II) tris(bipyridine) hemicage complex exhibiting a significant long-lived ${ }^{3}$ MLCT emission with a lifetime value of $2.1 \mu \mathrm{s}[13]$.

\section{PYRENE-2,2'-BIPYRIDINE CONJUGATED MOLECULAR RODS}

The design and synthesis of molecular systems in which the fluorophore and receptor moieties are rigidly con- 
Table 1. Spectroscopic and photophysical data in acetonitrile at $298 \mathrm{~K}$ (degassed solutions using freeze-pump-thaw technique, not determined due to spectral overlap).

\begin{tabular}{|c|c|c|c|c|c|c|c|}
\hline \multirow[b]{2}{*}{ Compound } & \multicolumn{4}{|c|}{ Absorption } & \multicolumn{3}{|c|}{ Emission } \\
\hline & $\lambda_{\max }(\mathrm{nm})$ & $\varepsilon_{\max }\left(\mathrm{M}^{-1} \mathrm{~cm}^{-1}\right)$ & state & chromophore & $\lambda_{\max }(\mathrm{nm})$ & $\tau(\mathrm{ns})$ & $\Phi_{\mathrm{em}}$ \\
\hline \multirow[t]{4}{*}{1} & 341 & 46650 & ${ }^{1} \mathrm{~L}_{\mathrm{a}}$ & pyrene & 375 & 205 & 0.60 \\
\hline & 279 & $*$ & $\pi-\pi^{*}$ & bpy & & & \\
\hline & 275 & * & ${ }^{1} \mathrm{~B}_{\mathrm{b}}$ & pyrene & & & \\
\hline & 242 & $*$ & ${ }^{1} \mathrm{~B}_{\mathrm{a}}$ & pyrene & & & \\
\hline \multirow[t]{5}{*}{ 1-Ru } & 452 & 11000 & MLCT & $\mathrm{Ru}$ & 610 & 10500 & 0.065 \\
\hline & 342 & 30500 & ${ }^{1} \mathrm{~L}_{\mathrm{a}}$ & pyrene & & & \\
\hline & 291 & $*$ & $\pi-\pi^{*}$ & $\mathrm{Ru}$ & & & \\
\hline & 277 & * & ${ }^{1} \mathrm{~B}_{\mathrm{b}}$ & pyrene & & & \\
\hline & 243 & * & ${ }^{1} \mathrm{~B}_{\mathrm{a}}$ & pyrene & & & \\
\hline \multirow[t]{3}{*}{ 1-Et pyrene } & 341 & 43800 & ${ }^{1} \mathrm{~L}_{\mathrm{a}}$ & & 375 & 193 & 0.64 \\
\hline & 274 & 60000 & ${ }^{1} \mathrm{~B}_{\mathrm{a}}$ & & & & \\
\hline & 241 & 85000 & ${ }^{1} \mathrm{~B}_{\mathrm{a}}$ & & & & \\
\hline \multirow[t]{2}{*}{$\overline{\left[\mathrm{Ru}(\mathrm{bpy})_{3}\right]^{2+}}$} & 452 & 13600 & MLCT & & 609 & 890 & 0.063 \\
\hline & 288 & 76600 & $\pi-\pi^{*}$ & & & & \\
\hline
\end{tabular}

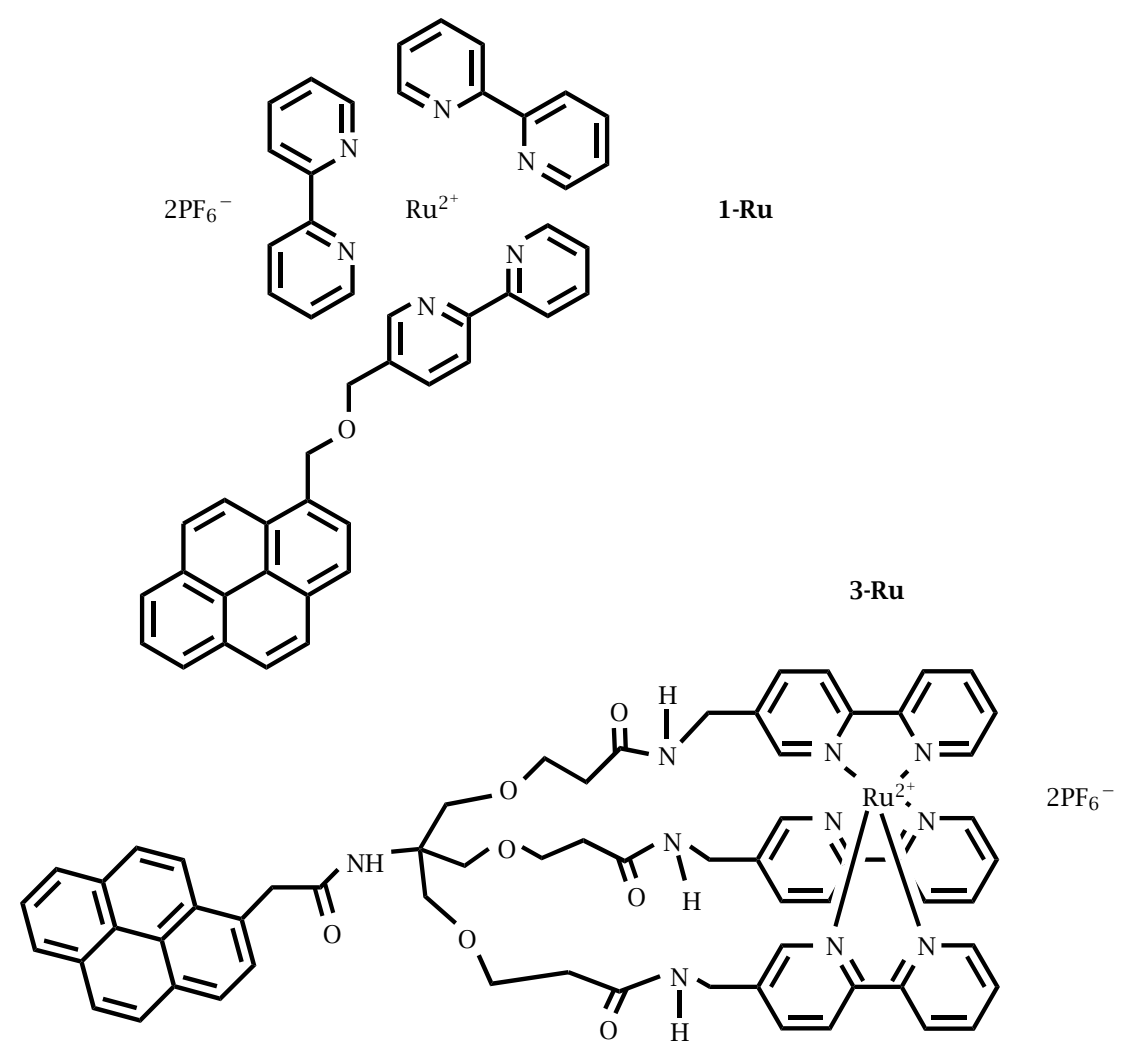

Scheme 2. 
Table 2. Photophysical data for conjugated rods in THF $\left(25^{\circ} \mathrm{C}\right)$.

\begin{tabular}{lcccr}
\hline Compound & $\lambda_{\max }($ Abs) $(\mathrm{nm})$ & $\lambda_{\max }($ Fluo $)(\mathrm{nm})$ & $\Phi_{\mathrm{f}}$ & $\tau(\mathrm{ns})$ \\
\hline $\mathbf{4}$ & 344 & 394 & 0.47 & 6.5 \\
$\mathbf{5}$ & 411 & 442 & 0.68 & 1.7 \\
$\mathbf{5 - Z n}$ & 420 & 578 & 0.40 & 2.8 \\
\hline
\end{tabular}<smiles>c1ccc(-c2cc(-c3ccc4ccc5cccc6ccc3c4c56)ccn2)nc1</smiles><smiles>CCCCOc1cc(C#Cc2ccc3ccc4cccc5ccc2c3c45)c(OCCCC)cc1C#Cc1ccnc(-c2ccccn2)c1</smiles><smiles></smiles>

Scheme 3.

nected by a conjugated bridge represent a promising approach toward rod-like multicomponent molecules with well-defined shape and length. In such systems, high degree of electronic communication may be ensured, which provides for geometrically controlled, efficient intramolecular charge and/or electronic excitation transport properties [14] at the molecular level. With this in mind, we directed our research effort toward the generation of molecular rods in which the pyrene and bpy terminal units are linked by a conjugated bridge. Two prototypical systems are presented therein. In compound 4 , the bridge is a single $\mathrm{C}-\mathrm{C}$ bond [15], whereas in compound 5 , the spacer is a $p$ phenylene-ethynylene group [16]. In the latter, the presence of the 2,5-dialkyloxy-1,4-phenylene aromatic moiety was also anticipated to endow compound 5 with im- proved solubility. Actually, the outstanding potential of such rodlike ligands as photoactive molecular systems has been reported in literature $[17,18]$.

The photophysical data for compounds 4 and 5 are collected in Table 2. They show the strong influence of the conjugated bridge on the electronic absorption and fluorescence emission features of the free ligands relative to the non-conjugated systems (Table 1). Compound 5, with an extended conjugation in the ground and excited states, exhibits broad, red-shifted absorption and fluorescence spectra as compared to those obtained for 4. Actually, it was shown that the fluorescence emission in the latter was dependent on the polarity of the solvent, and appeared to originate from intermixing forbidden ${ }^{1} \mathrm{~L}_{b}$ and allowed ${ }^{1} \mathrm{~L}_{a}$ states. The extent of electronic intermixing was connected to the 
angular torsion angle value around the $\mathrm{C}-\mathrm{C}$ bond between pyrene and bpy moieties [19]. In compound $\mathbf{5}$ however, stabilization of the ${ }^{1} \mathrm{~L}_{\mathrm{a}}$ state is much more effective, thereby leading to high values of the fluorescence quantum yields and lifetimes that were found to be insensitive to the nature of the solvent.

Remarkably, a spectacular modulation of emission wavelengths can be attained by the addition of metal ions, such as Zinc(II), to solutions of ligand 5. A shift of approximately $140 \mathrm{~nm}$ is observed upon addition of $\mathrm{Zn}^{2+}$ ions to ligand 5 in THF, yielding an intense orange emission. Furthermore the fluorescence emission maximum of the isolated 1: 1 5-Zn complex was shown to undergo a dramatic solvatochromic shift, which is typical of donor/acceptor molecules having a highly polar excited state. Indeed, the terminal bpy ligand bound to zinc(II) in the complex 5-Zn becomes a strong electron withdrawing group, which promotes intramolecular charge transfer (ICT) state formation. From the dependence of the fluorescence emission maximum upon solvant polarity, a value greater than $25 \mathrm{D}$ was obtained for the excited-state dipole moment of the ICT state in $\mathbf{5 - Z n}$.

The conjugated rods are also considerably attractive as ligand building-blocks for the generation of photoactive ruthenium(II) species. This was demonstrated in the case of compound 4 [18], leading to considerable prolongation of the MLCT excited state of the $\left[\mathrm{Ru}(\mathrm{bpy})_{3}\right]^{2+}$ chromophore. The study of ruthenium(II) complexes of ligand $\mathbf{5}$ and related systems is currently the subject of intense investigation.

\section{CONCLUSION AND OUTLOOKS}

This accounts was intended to describe the complexation and spectroscopic behavior of a selected series of pyrene-bipyridine systems, and to show the variety of photophysical responses that can be triggered by metal ion complexation. Indeed these compounds represent highly emissive tunable fluorophores which can serve as promising systems with versatile optical properties desirable for molecular photonic materials, particularly light-emitting devices. Conjugated molecular rods appear especially appealing as they display intense visible emission upon excitation at long wavelengths $(>400 \mathrm{~nm}$ ), and allow the generation of metal ion complexes with remarkable spectroscopic signatures, such as long-lived luminescence in the case of ruthenium(II) complexes. These features might provide new opportunities in the fields of luminescence-based chemosensing, luminogenic assays, or photochemical conversion and storage of solar energy.

\section{ACKNOWLEDGEMENTS}

We are grateful to Professors R. H. Schmehl and L. De Cola for fruitful discussions. T. S. thanks the CNRS for granting a postdoctoral fellowship. The CNRS, Univer- sity Bordeaux 1, and La Région Aquitaine are gratefully acknowledged for financial support.

\section{REFERENCES}

[1] A. Laurent, Ann. Chim. Phys. 66 (1837), 136.

[2] J.-M. Lehn, Supramolecular Chemistry, VCH, Weinheim 1995.

[3] A. P. de Silva, H. Q. N. Gunaratne, T. Gunnlaugsson, A. J. M. Huxley, C. P. McCoy, J. T. Rademacher, and T. E. Rice, Chem. Rev. 97 (1997), 1515.

[4] Chemosensors of Ion and Molecule Recognition, J.P. Desvergne, and A. W. Czarnik (eds.), NATO ASI series; Vol. 492, Kluwer Academic Publishers: Dordrecht, The Netherlands, 1997.

[5] C. Bargossi, M. C. Fiorini, M. Montalti, L. Prodi, and N. Zaccheroni, Coord. Chem. Rev. 208 (2000), 17.

[6] J.-E. Sohna Sohna, PhD Thesis, University Bordeaux 1, France, 1997.

[7] J.-E. Sohna Sohna, P. Jaumier, and F. Fages, J. Chem. Res. (S) 134 (1999).

[8] F. Fages, S. Leroy, T. Soujanya, and J.-E. Sohna Sohna, Pure Appl. Chem., in press.

[9] Ligand 1 was obtained according to a classical alkylation procedure starting from 1hydroxymethyl-pyrene and 5-bromomethyl-2,2'bipyridine and using $\mathrm{NaH}$ as a base and DMF as solvent (22\% isolated yield). M.p. $133^{\circ} \mathrm{C}$. Anal. calcd for $\mathrm{C}_{28} \mathrm{H}_{20} \mathrm{~N}_{2} \mathrm{O}: 0.5 \mathrm{H}_{2} \mathrm{O}: \mathrm{C}, 82.13 ; \mathrm{H}, 5.16$; $\mathrm{N}, 6.84$. Found: $\mathrm{C}, 82.64 ; \mathrm{H}, 5.10 ; \mathrm{N}, 6.98$. The ruthenium(II) complex 1-Ru was obtained in 60\% yield by refluxing an equimolar mixture of $\mathbf{1}$ and cis- $\mathrm{Ru}(\mathrm{bpy})_{2} \mathrm{Cl}_{2}$ in ethylene glycol. Anal. calcd for $\mathrm{C}_{48} \mathrm{H}_{36} \mathrm{~N}_{6} \mathrm{O}_{3} \mathrm{P}_{2} \mathrm{~F}_{12}: 1 \mathrm{H}_{2} \mathrm{O}: \mathrm{C}, 51.39 ; \mathrm{H}, 3.41 ; \mathrm{N}$, 7.49. Found: C, 51.44; H, 3.34; N, 7.30 .

[10] A. P. de Silva, I. M. Dixon, H. Q. N. Gunaratne, T. Gunnlaugsson, P. R. S. Maxwell, and T. E. Rice, J. Am. Chem. Soc. 121 (1999), 1393.

[11] D. S. Tyson, J. Bialecki, and F. N. Castellano, Chem. Commun. 2355 (2000), and references therein.

[12] H. Bouas-Laurent, A. Catellan, J.-P. Desvergne, and R. Lapouyade, Chem. Soc. Rev. 19 (2000), 43.

[13] J.-E. Sohna Sohna, V. Carrier, F. Fages, and E. Amouyal, submitted.

[14] P. H. F. Schwob, M. D. Levin, and J. Michl, Chem. Rev. 99 (1999), 1863.

[15] A. L. Rodriguez, G. Peron, C. Duprat, M. Vallier, E. Fouquet, and F. Fages, Tetrahedron Lett. 39 (1998), 1179.

[16] S. Leroy, T. Soujanya, and F. Fages, Tetrahedron Lett. 42 (2001), 1665.

[17] M. Hissler, A. Harriman, A. Khatyr, and R. Ziessel, Chem. Eur. J. 5 (1999), 3366.

[18] J. A. Simon, S. L. Curry, R. H. Schmehl, T. R. Schatz, P. Piotrowiak, X. Jin, and R. P. Thummel, J. Am. Chem. Soc. 119 (1997), 11012.

[19] T. Soujanya, A. Philippon, S. Leroy, M. Vallier, and F. Fages, J. Phys. Chem. A 104 (2000), 9408. 


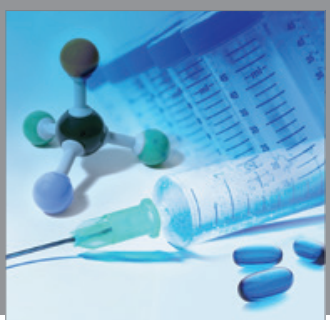

International Journal of

Medicinal Chemistry

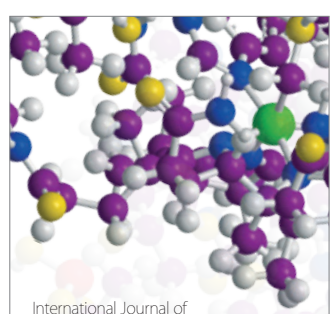

Carbohydrate Chemistry

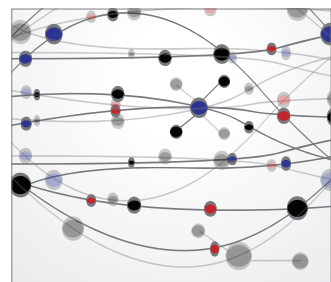

The Scientific World Journal
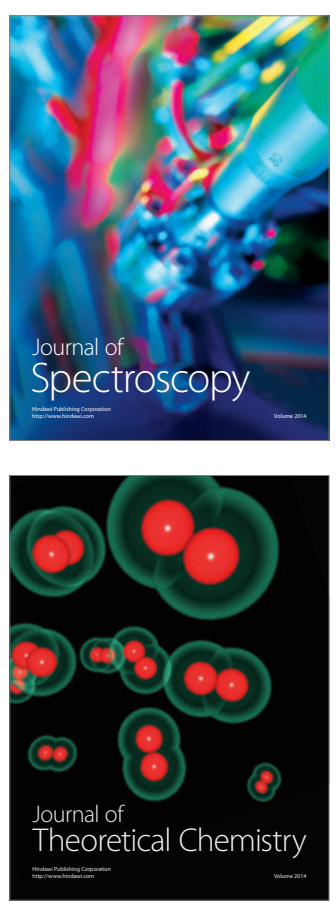
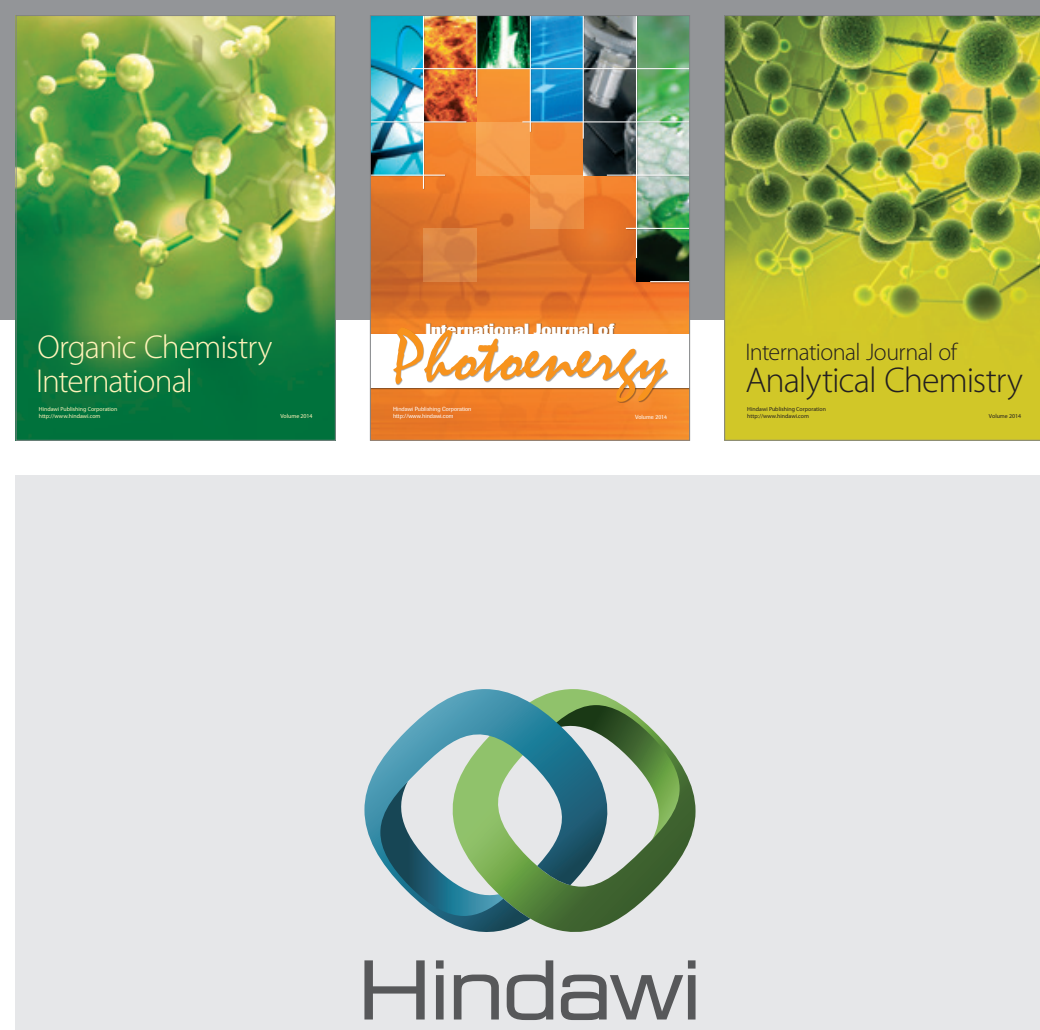

Submit your manuscripts at

http://www.hindawi.com
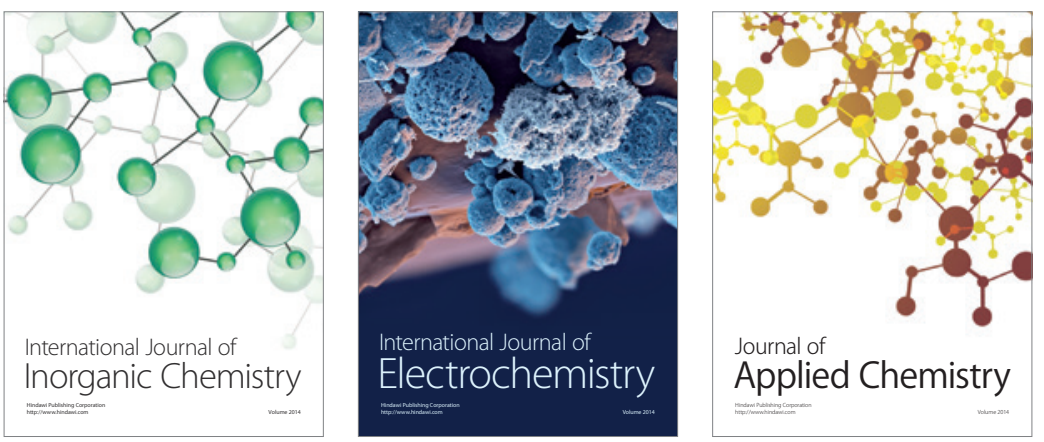

Journal of

Applied Chemistry
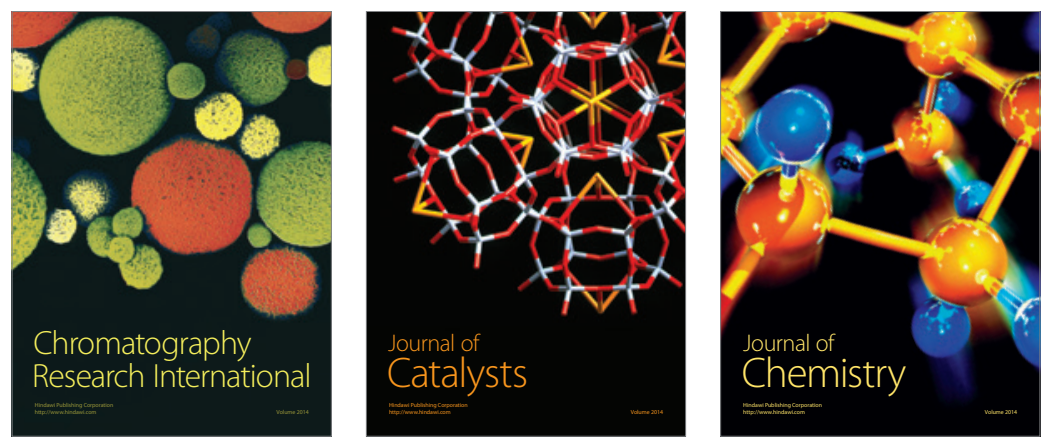
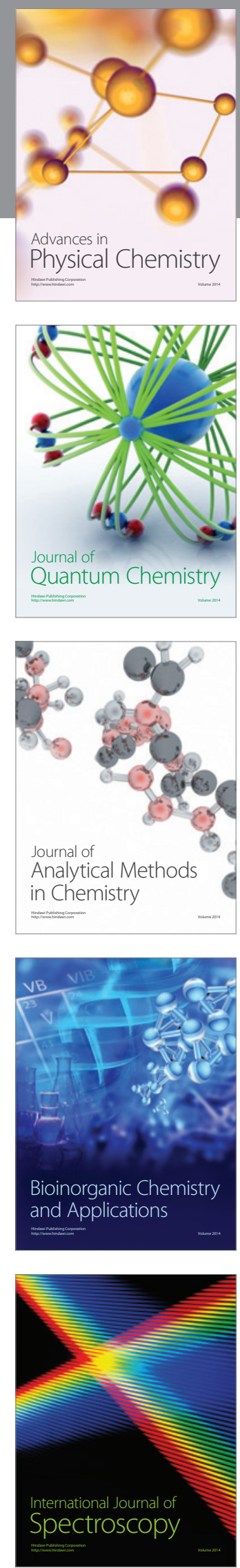